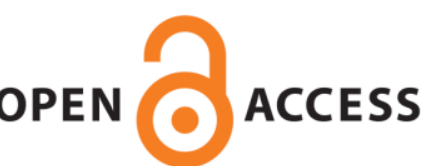

OPEN ACCESS

UWS Academic Portal

\title{
Foot motion character during forward and backward walking with shoes and barefoot
}

Sun, Dong; Fekete, Gusztáv; Baker, Julien S.; Gu, Yaodong

Published in:

Journal of Motor Behavior

DOI:

$10.1080 / 00222895.2019 .1605972$

E-pub ahead of print: 25/04/2019

Document Version

Peer reviewed version

Link to publication on the UWS Academic Portal

Citation for published version (APA):

Sun, D., Fekete, G., Baker, J. S., \& Gu, Y. (2019). Foot motion character during forward and backward walking with shoes and barefoot. Journal of Motor Behavior, 52(2), 214-225.

https://doi.org/10.1080/00222895.2019.1605972

\section{General rights}

Copyright and moral rights for the publications made accessible in the UWS Academic Portal are retained by the authors and/or other copyright owners and it is a condition of accessing publications that users recognise and abide by the legal requirements associated with these rights.

Take down policy

If you believe that this document breaches copyright please contact pure@uws.ac.uk providing details, and we will remove access to the work immediately and investigate your claim. 
"This is an Accepted Manuscript of an article published by Taylor \& Francis Group in Journal of Motor Behavior on 25/04/2019, available online: https://

doi.org/10.1080/00222895.2019.1605972." 
1 Title: Foot motion character during forward and backward walking with shoes and barefoot

2

3 Dong Sun ${ }^{1,2,3}$, Gusztáv Fekete ${ }^{1,2}$, Julien S.Baker ${ }^{4}$, Yaodong $\mathrm{Gu}^{1 *}$

$4 \quad{ }^{1}$ Faculty of Sports Science, Ningbo University, Ningbo, China.

$5 \quad 2$ Savaria Institute of Technology, Eötvös Loránd University, Szombathely, Hungary.

$6 \quad{ }^{3}$ Faculty of Engineering, University of Pannonia, Veszprem, Hungary.

$7{ }^{4}$ Institute for Clinical Exercise and Health Science, University of the West of Scotland, 8 Lanarkshire, United Kingdom.

\section{Corresponding author}

Prof. Yaodong Gu, PhD

Address: Faculty of Sports Science, Ningbo University. No. 818, Fenghua Road, Jiangbei

District, Ningbo, Zhejiang. China. 315211

Email: guyaodong@hotmail.com

\section{Funding details}

This work was supported by the National Natural Science Foundation of China under Grant (81772423), the Hungary-China Doctoral Research Scholarship under Grant (201700500099)

K. C. Wong Magna Fund in Ningbo University, and National Social Science Foundation of China (16BTY085).

\section{Disclosure statement}

No potential conflict of interest was reported by the authors. 


\section{Abstract}

Backward walking (BW) has been extensively used in athletic training and orthopedic rehabilitation as it may be valuable for enhancing balance. The present study identified the differences in foot inter-segment kinematics (forward walking (FW) vs. time-reversed BW) and plantar pressure parameters of sixteen healthy habitually shod individuals walking FW and BW with flexible shoes (SH) and barefoot (BF). BW was found to have shorter stride length (SL) and higher stride frequency (SF) under BF conditions compared with SH, which indicates a better BW gait stability under BF conditions. Decreased HX/FF dorsiflexion at HO in BW walking induced less plantar aponeurosis tension which may inhibit the windlass mechanism compared to FW walking. Increased forefoot relative to hindfoot (FF/HF) pronation and sequentially hindfoot relative to tibia (HF/TB) eversion combined with medially distributed plantar pressure and higher plantar contact area in the medial side in BW-BF maybe beneficial to maintain balance. These results indicate that BW training may be more reliable under BF conditions compared to SH conditions based on more sensory information feedback from the plantar area and better biomechanical behavior.

Keywords: Foot kinematics, Backward walking, Shoes, Barefoot 


\section{Introduction}

Forward walking (FW) and backward walking (BW) have been researched extensively in the past twenty years, distinct advantages of BW were found over FW for both fitness training and rehabilitation (Grasso, Bianchi, \& Lacquaniti, 1998)(Sedhom, 2017). During BW, the absence of visual cues and peripheral visual feedback implies that BW relies more heavily on proprioception than FW. The variation in visual information, as well as the simple novelty of the task may require a remodeling of sensory feedback to maintain dynamic balance. Therefore, BW has been used as an intervention for enhancing balance to improve mobility function after stroke(D. A. Winter, Pluck, \& Yang, 1989)(Tseng, Jeng, \& Yuan, 2012). BW has less mechanical strain on the knee joint, which has been used in orthopedic rehabilitation and in increasing the strength and power of the quadriceps(Rose, Demark, Fox, Clark, \& Wludyka, 2018). FW and time-reversed BW showed similar gait patterns and the characteristics of angular displacement in all lower limb joints during the gait cycle. Thus, the similarity led some researchers to suggest that the neural control may originate from the same "spinal" automatisms in each walking pattern(Van Deursen, Flynn, McCrory, \& Morag, 1998). However, some findings do not agree with this suggestion. Some studies have recorded differences in knee and ankle angular displacement, joint torques and electromyography (EMG) between FW and time-reversed BW patterns(Shu et al., 2016)(Jansen et al., 2012). Reversing walking direction from FW to BW was found in slower walking speeds and shorter stride length among both young and older adults(Fritz et al., 2013). BW was reported more variable compared to FW, more specifically, knee and hip range of motion (ROM) presented to be more variable during BW. BW is suggested to have lower local dynamic stability than 
FW, which makes BW a more demanding task of motion control(Katsavelis, Mukherjee, Decker, \& Stergiou, 2010)(Bollens, Crevecoeur, Detrembleur, Warlop, \& Lejeune, 2014).

The foot plantar contains 104 cutaneous mechanoreceptors and the receptor is primarily distributed where the foot is in contact with the ground(Kennedy \& Inglis, 2002). Backward barefoot walking may provide more tactile feedback from the foot sole which compensates for limited visual input. Footwear was found to hinder the kinesthesia while walking barefoot has demonstrated greater awareness of foot position and movement control compared with wearing athletic footwear(Morio, Lake, Gueguen, Rao, \& Baly, 2009). Walking with various types of shoe and barefoot was found to affect the FW pattern and balance control. Flatter foot placement and increased forefoot spreading were reported during barefoot walking(Chard, Greene, Hunt, Vanwanseele, \& Smith, 2013). Habitual barefoot walkers exhibit increased knee flexion, reduced peak vertical ground reaction force and peak plantar pressures(D’Août, Pataky, De Clercq, \& Aerts, 2009). These studies suggest that footwear may be interfering with the functional ability of the human foot. Winter et al., (D. a. Winter, 1984)demonstrated that similar knee and hip angle patterns but different ankle angle patterns exist between FW and BW. A single foot segment model may disregard the important inter-segmental motion that occurs within the foot, the foot bend and torsion are obscured. Thus, for clinical gait analysis and human movement research, the traditional one segment foot model is beginning to be replaced by various multi-segment foot models (MSFM). The addition of kinematics to the multi-segment model may provide additional insight into the foot and ankle complex functions(Pothrat, Authier, Viehweger, Berton, \& Rao, 2015). However, no studies to date have compared the foot inter-segment kinematics of FW and BW with shoes (SH) and barefoot (BF). 
94

The purpose of this study was to examine the differences on foot inter-segment kinematics, and plantar pressures of healthy individuals walking forward and backward with shoes or barefooted. We hypothesized that the foot inter-segment motions of hindfoot, forefoot, and hallux will vary significantly between FW and time-reversed BW and substantial asymmetrical differences exist especially in the sagittal and frontal planes, the foot motions under shod conditions will be constrained significantly compared with barefoot conditions. We also hypothesized that the plantar pressure would be redistributed under the foot sole during BW, wearing shoes may significantly decrease plantar pressures during both FW and BW patterns.

\section{Methods}

\section{Subjects}

Sixteen healthy male subjects (age: $25.75 \pm 2.62$ years, height: $1.72 \pm 0.62 \mathrm{~m}$, weight: $66.78 \pm 7.20$ kg, BMI: $22.57 \pm 0.71 \mathrm{~kg} / \mathrm{m}^{2}$ ) volunteered to take part in this study. The inclusion criteria of the subjects were no abnormal findings on a foot X-ray radiograph and no history of fracture or surgery in the lower limbs. All participants were without any musculoskeletal injury or pain during the data collection period. All the subjects were rear-foot strikers and the dominant foot was the right one based on the test of kicking a soccer ball, so all statistics concerning the tests are based on data from the right feet of all subjects(Sun, Mei, Baker, Jia, \& Gu, 2017). The subjects wore the same sock and shoe model with flat outsoles and without any cushioning system. The shoes were fitted according to their foot size. The subjects provided written informed consent to participate in this study. Ethical approval was obtained from the Ethics committee of Ningbo University (No. ARGH 20171124). 


\section{Instrumentation setup}

117 An eight MX-Cameras VICON motion analysis system (Oxford Metrics Ltd., Oxford, UK) were used to capture the foot inter-segment kinematics at a frequency of $200 \mathrm{~Hz}$. Calibration of the motion capture system was performed before the gait trials. A $0.6 \mathrm{~m} \times 0.8 \mathrm{~m}$ force plate (AMTI, Watertown, USA) was fixed into the middle of the walkway and utilized to obtain the GRF data at a frequency of $1000 \mathrm{~Hz}$ (Figure 1). The marker trajectories and force plate data 
al(Stebbins, Harrington, Thompson, Zavatsky, \& Theologis, 2006). A set of 36 markers (9 mm) were placed bilaterally on bony landmarks to model the tibia, hindfoot, forefoot, and hallux(Wang, Thur, Gutierrez-Farewik, Wretenberg, \& Broström, 2010). 20mm holes were cut in the shoe upper material to obtain in-shoe foot kinematics, the position of each hole was referenced to the underlying anatomical landmarks based on the OFM(Wolf et al., 2008). Good consistency in kinematic waveform estimation and good intra-rater reliability of the in-shoe multi-segment foot kinematics were approved in previous studies. The OFM used in this study simplified complex anatomical foot structures to three rigid segments (tibia, hindfoot and forefoot) and one vector (hallux). Foot kinematics and plantar pressure data were measured and time synchronized in this study. During plantar pressure measurement, the plantar insoles were secured to the participants' feet with double-sided tape, and a standardized thin cotton sock was worn to incorporate plantar pressure insoles under barefoot condition. When shod walking, the insoles were placed in the shoes. Pressure insoles were placed bilaterally and are designed in different sizes to adjust the foot and shoe size in this test. A pressure pump was used to calibrate all the insoles used in this experiment to minimize the error during measurement. Ten successful trails were selected for further analysis under each condition.

\section{Data analysis}

Walking speed was calculated as the anterior-superior displacement of the anterior-superior iliac spine marker (PIG model) divided by the corresponding time. Stride length (SL) was recorded as the anterior-posterior distance between the right heel marker (RHEE) in one gait cycle. Stride frequency (SF) was computed as the inverse of one gait cycle duration(Fu et al., 2016). Stance time (ST) was calculated as the duration from the right foot strike onto the force 
platform to the right foot move off the platform. The stance phase of FW was defined as the duration from right foot heel-contact (HC) to toe-off (TO). Conversely, the stance phase of BW was defined from toe-contact (TC) to heel-off (HO). FW (HC/TO) and BW (HO/TC) had opposite contact positions (heel/toe) for the same gait events (initial contact/push-off). Therefore, time-reversed foot inter-segment angle curves of BW were used to compare the kinematic pattern of FW to adjust for the purpose of this study. Foot kinematics were time normalized to $0-100 \%$ of the stance phase. The right side (dominant) walking pattern during one stance phase was analyzed for all kinematic and kinetic variables. Marker trajectory was captured, tracked and labeled in VICON Nexus and post-processing performed in Visual 3D (C-Motion Inc., USA). The foot kinematics were filtered with a fourth-order zero-phase lag Butterworth filter having a cutoff frequency of $12 \mathrm{~Hz}$. The foot inter-segment angles were calculated according to the method proposed by Grood and Suntay (flexion, adduction, and rotation)(Grood \& Suntay, 1983). The following foot inter-segment kinematic variables were selected in this study: hindfoot relative to tibia (HF/TB), forefoot relative to hindfoot (FF/HF) and hallux relative to forefoot (HX/FF, sagittal plane only). For foot kinematic variables, angle values at $\mathrm{HC} / \mathrm{HO}$ and $\mathrm{TO} / \mathrm{TC}$, as well as peak angles and range of motion (ROM) values in the stance phase were derived(Mei, Fernandez, Fu, Feng, \& Gu, 2015). The foot was divided into seven anatomical regions: including big toe (BT), other toes (OT), medial forefoot (MFF), central forefoot (CFF), lateral forefoot (LFF), midfoot (MF) and heel (H). Variables include peak pressure (peak pressure distributed to each region measures from pressure insole) and contact area (the number of the pressure insole sensors activated).

\section{Statistical analysis}


Statistical analysis was conducted using a commercial statistical package (SPSS 22.0, SPSS Inc., Chicago, IL, USA). Shapiro-Wilks test was used to check the normality of each variable and that each one was normally distributed. A two-way ANOVA (forward/backward walking $\times$ barefoot/shod condition) with post-hoc Bonferroni pair-wise comparisons to examine spatiotemporal parameters including walking speed, SL, SF and ST; foot inter-segment kinematics including initial contact angles, peak angles, push-off angles and ROM; foot subregion peak plantar pressures and contact area. Bonferroni post-hoc pair-wise comparisons were carried out to provide details of significant differences. Data are presented as Mean \pm Standard Deviation (SD). All significance levels were set at $\mathrm{p}=0.05$.

\section{Results}

\section{Spatial-temporal parameters}

Main effects of FW/BW walking patterns

There was a significant decrease in walking speed $(\mathrm{BF}: \mathrm{p}=0.026 ; \mathrm{SH}: \mathrm{p}=0.013$, post-hoc test) and stride frequency (SF) (BF: $\mathrm{p}=0.007 ; \mathrm{SH}=0.016)$ during $\mathrm{BW}$, relative to $\mathrm{FW}$. On the contrary, a significant increase in stride length (SL) $(\mathrm{BF}: \mathrm{p}=0.002 ; \mathrm{SH}: \mathrm{p}=0.005)$ and stance time (ST) (BF: $\mathrm{p}=0.013$; $\mathrm{SH}: \mathrm{p}=0.004)$ were found in BW compared with FW (Table 1).

\section{Main effects of BF/SH conditions}

Significantly higher SL was found under shod condition during both FW and BW (FW: $\mathrm{p}=0.021 ; \mathrm{BW}: \mathrm{p}=0.009)$. However, there was a significantly decreased SF under shod condition during FW and BW (FW: $\mathrm{p}=0.023$; $\mathrm{BW}$ : $\mathrm{p}=0.018$ ), relative to BF condition. Interactions 
There were no statistically significant interactions $(\mathrm{p}=0.088-0.909)$ between $\mathrm{FW} / \mathrm{BW}$ patterns and $\mathrm{BF} / \mathrm{SH}$ conditions for the spatiotemporal parameters.

---Insert Table 1 near here---

\section{Foot inter-segment kinematics}

Foot inter-segment kinematic patterns of the hindfoot relative to tibia (HF/TB), forefoot relative to hindfoot (FF/HF), and hallux relative to forefoot $(\mathrm{HX} / \mathrm{FF})$ are plotted against percent of stance for the FW and time-reversed BW patterns under BF/SH conditions (Figure 2). The selected crucial points of foot angle characteristics of HF/TB, FF/HF and HX/FF are presented in Table 2, Table 3 and Table 4, respectively.

Main effects of FW/BW walking patterns

For the HF/TB angles, in the sagittal plane, $\mathrm{HC} / \mathrm{HO}$ angles were significantly decreased (BF: $\mathrm{p}<0.001$; SH: $\mathrm{p}=0.002$ ) in BW compared with FW. Significant increase of maximum HF/TB dorsiflexion angle (BF: $\mathrm{p}<0.001$; SH: $\mathrm{p}<0.001$ ) and DF/PF ROM (BF: $\mathrm{p}=0.003$; SH: $\mathrm{p}=0.001$ ) in this plane existed in BW, relative to FW. In the frontal plane of HF/TB, the $\mathrm{HC}$ angles in FW under $\mathrm{BF}$ and $\mathrm{SH}$ conditions were $-1.8 \pm 4.3^{\circ}$ and $-3.0 \pm 5.1^{\circ}$. Note that a negative angle value is defined as eversion, therefore an eversion tendency of $\mathrm{HF} / \mathrm{TB}$ motion was found in the $\mathrm{HC}$ during FW compared to BW in the HO. Significantly greater maximum HF/TB inversion (BF: $\mathrm{p}=0.005$; SH: $\mathrm{p}=0.002$ ) was found in BW compared with FW. In the transverse plane of HF/TB, external rotation in $\mathrm{HO}$ was also found in $\mathrm{BW}$ in comparison with $\mathrm{FW}$ in $\mathrm{HC}$ under both conditions. Significant decrease of peak internal rotation (BF: $\mathrm{p}=0.013$; $\mathrm{SH}: \mathrm{p}=0.018$ ), peak 
external rotation $(\mathrm{BF}: \mathrm{p}<0.001$; $\mathrm{SH}: \mathrm{p}=0.004)$ and IR/ER ROM (BF: $\mathrm{p}<0.001 ; \mathrm{SH}: \mathrm{p}<0.001)$ in

227 this plane existed in BW compared FW. For the FF/HF angles, in the sagittal plane, the plantarflexion/dorsiflexion was significantly different at TO/TC. Pairwise comparisons revealed the forefoot dorsiflexion with respect to hindfoot in BW significantly greater than FW at TO/TC (BF: $\mathrm{p}<0.001 ; \mathrm{SH}: \mathrm{p}<0.001)$. In the frontal plane of $\mathrm{FF} / \mathrm{HF}$, significantly greater peak pronation (BF: $p=0.021$; $\mathrm{SH}: \mathrm{p}=0.033$ ) was shown in BW compared with $\mathrm{FW}$. The TO/TC pronation angles in BW showed significantly more pronated $(B F$ : $p<0.001$; $S H$ : $p<0.001$ ) comparison with FW. In the transverse plane of $\mathrm{FF} / \mathrm{HF}$, BW was at a more abducted position in HO. A significant decrease of FF/HF peak ADD (BF: $\mathrm{p}<0.001$; $\mathrm{SH}: \mathrm{p}<0.001)$ and ROM $(\mathrm{ABD} / \mathrm{ADD})(\mathrm{BF}: \mathrm{p}=0.015 ; \mathrm{SH}: \mathrm{p}=0.027)$ at $\mathrm{TO} / \mathrm{TC}$ was found in comparison with between BW and FW. For the HX/FF angles, only sagittal plane included for analysis. A significant decrease of dorsiflexion angle (BF: $\mathrm{p}<0.001$; $\mathrm{SH}: \mathrm{p}<0.001)$ at $\mathrm{HC} / \mathrm{HO}$ was found in $\mathrm{BW}$ at both conditions. The maximum dorsiflexion angle in FW was found significantly greater (BF: $\mathrm{p}<0.001)$ compared to BW only under BF condition. The peak plantarflexion angle (BF: $\mathrm{p}<0.001$; SH: $\mathrm{p}<0.001$ ) in BW were found significantly higher than FW. However, DF/PF ROM of HX/FF showed significantly lower in BW under BF condition (BF: $\mathrm{p}<0.001)$.

Main effects of BF/SH conditions

For the HF/TB angles, in the sagittal plane, SH walking showed a greater peak DF angle (FW: $\mathrm{p}=0.012$; $\mathrm{BW}: \mathrm{p}=0.008$ ) compared with $\mathrm{BF}$ walking. While SH walking showed significantly smaller peak PF angle (FW: $\mathrm{p}=0.021$; $\mathrm{BW}$ : $\mathrm{p}=0.016$ ) compared with BF walking in both walking patterns. In the frontal plane of $\mathrm{HF} / \mathrm{TB}$, at $\mathrm{HC} / \mathrm{HO}$, SH walking was less dorsiflexed ( $F W: p=0.022)$ in $F W$ and more plantar-flexed $(B W: p=0.017)$ in $B W$ compared with $B F$ 
walking. For the FF/HF angles, in the sagittal plane, the TO/TC angles were found more dorsiflexed (FW: $\mathrm{p}<0.001$; $\mathrm{BW}: \mathrm{p}=0.011)$ in $\mathrm{SH}$ walking compared to $\mathrm{BF}$ walking. In the frontal plane of $\mathrm{FF} / \mathrm{HF}$, peak pronation angles of SH walking were significantly greater (FW: $\mathrm{p}=0.023$; $\mathrm{BW}: \mathrm{p}=0.031$ ) than $\mathrm{BF}$ walking. In the transverse plane of $\mathrm{FF} / \mathrm{HF}$ angles, the $\mathrm{HC} / \mathrm{HO}$ angles were presented more abducted $(\mathrm{FW}: \mathrm{p}=0.007$; $\mathrm{BW}: \mathrm{p}<0.001)$ in $\mathrm{SH}$ compared to $\mathrm{BF}$ walking. Significantly decreased peak adduction angles (FW: $p=0.005 ; \mathrm{BW}: \mathrm{p}=0.009$ ) of SH walking existed compared to BF walking at both walking patterns. For the HX/FF sagittal plane angles, a significantly smaller dorsiflexion angles (FW: $\mathrm{p}=0.022$; $\mathrm{BW}: \mathrm{p}=0.012$ ) at $\mathrm{HC} / \mathrm{HO}$ were shown in $\mathrm{SH}$ condition compared to $\mathrm{BF}$ condition. Post-hoc analysis indicated less dorsiflexion (FW: $\mathrm{p}<0.001)$ in $\mathrm{SH}$ condition during FW pattern. The HX/FF ROM was also significantly smaller (FW: $\mathrm{p}<0.001)$ in SH condition compared with BF condition only during FW walking pattern.

Interactions

For the HF/TB angles, There was a Pattern $\times$ Condition interaction $(F=7.593, p=0.022)$ existed in the $\mathrm{HC} / \mathrm{HO}$ angle in the frontal plane of $\mathrm{HF} / \mathrm{TB}$. For the FF/HF angles, Pattern $\times$ Condition interactions were only found in the transverse plane. There was a Pattern $\times$ Condition interaction $(\mathrm{F}=28.261, \mathrm{p}<0.001)$ for the ADD/ABD ROM. For the HX/FF sagittal plane angles, there was a Pattern $\times$ Condition interaction $(F=24.643$, $\mathrm{p}<0.001)$ for the $\mathrm{DF} / \mathrm{PF} \mathrm{ROM}$.

---Insert Figure 2 near here---

---Insert Table 2 near here--- 
---Insert Table 3 near here---

---Insert Table 4 near here---

274

\section{Plantar pressures}

276 Peak pressure and contact area were collected in this study to evaluate foot loading characteristics of FW/BW patterns under BF/SH conditions. The comparison of peak pressure and contact area in the plantar sub-sections is shown in Figure 5 and Figure 6, respectively.

Main effects of FW/BW walking patterns

The peak pressure of BW was significantly higher in the big toe (BT) (BF: $<<0.001$; $\mathrm{SH}$ : $\mathrm{p}<0.001)$ and medial forefoot (MFF) (BF: $\mathrm{p}<0.001$; $\mathrm{SH}: \mathrm{p}<0.001)$ compared to $\mathrm{FW}$.

Conversely, peak pressure in other toes (OT) (BF: $\mathrm{p}<0.001$; $\mathrm{SH}: \mathrm{p}<0.001)$, midfoot (MF) (BF: $\mathrm{p}=0.012$; $\mathrm{SH}: \mathrm{p}=0.007)$ and heel $(\mathrm{H})(\mathrm{BF}: \mathrm{p}=0.023$; $\mathrm{SH}: \mathrm{p}<0.001)$ were significantly smaller in BW compared with FW. Significantly greater contact area were found in BT $(B F: p<0.001$; SH: $\mathrm{p}=0.006)$, MFF (BF: $\mathrm{p}=0.031 ; \mathrm{SH}: \mathrm{p}<0.001)$ and MF (BF: $\mathrm{p}=0.018$; $\mathrm{SH}: \mathrm{p}=0.003)$ in $\mathrm{BW}$ compared to FW. While greater contact area were found in OT (BF: $\mathrm{p}=0.011$; $\mathrm{SH}: \mathrm{p}=0.004$ ), lateral forefoot (LFF) (BF: $\mathrm{p}<0.001 ; \mathrm{SH}: \mathrm{p}<0.001)$ in FW compared to BW.

Main effects of BF/SH conditions

The peak pressure of SH condition was significantly decreased in central forefoot (CFF) (FW: $\mathrm{p}<0.001$; BW: $\mathrm{p}<0.001)$, lateral forefoot (LFF) (FW: $\mathrm{p}<0.001$; BW: $\mathrm{p}=0.004)$ and $\mathrm{H}(\mathrm{FW}$ : $\mathrm{p}=0.021$; BW: $\mathrm{p}<0.001)$ compared with BF condition. The contact area of the SH condition 
was found significantly increased in $\mathrm{OT}(\mathrm{FW}$ : $\mathrm{p}<0.001$; $\mathrm{BW}$ : $\mathrm{p}=0.007)$. While the $\mathrm{SH}$ condition showed reduced contact area in $\mathrm{MF}(\mathrm{FW}$ : $\mathrm{p}<0.001$; $\mathrm{BW}$ : $\mathrm{p}<0.001)$ and $\mathrm{H}(\mathrm{FW}$ : $\mathrm{p}=0.014$; $\mathrm{BW}$ : $\mathrm{p}=0.008$ ) compared with BF condition.

Interactions

Significant statistical interaction was only found in the peak pressure of the heel region, which showed a Pattern $\times$ Condition interaction $(F=24.654, \mathrm{p}<0.001)$ for this parameter.

---Insert Figure 3 near here---

---Insert Figure 4 near here---

\section{Discussion}

The purpose of this study was to analyze differences of FW and BW walking patterns under $\mathrm{BF}$ and SH conditions via caparisoning of biomechanical parameters. Previous studies have evaluated lower limb kinematics and kinetics of FW and time-reserved BW. This is the first study using a clinical multi-segment foot model to compare foot inter-segment kinematics of FW and time-reversed BW while walking with and without shoes.

In BW, since the absence of peripheral visual feedback and visual flow, the walking speed generally decreased compared to FW. Therefore, the spatiotemporal parameters showed a significant decrease during BW except for stride length, which was consistent with previous studies(Choi \& Bastian, 2007). Walking speed showed no significant difference between BF and SH conditions during both FW and BW walking. A reduction in gait speed was found when 
barefoot participants walking with their own habitual shoes in a previous study(Lythgo, Wilson, \& Galea, 2009). While a standardized flexible shoe was employed in this study, the familiarity of the shoes may potentially have a significant influence on gait biomechanics such as walking speed. Significantly lower stride length and higher stride frequency can be found under BF condition compared to SH condition in BW walking. Lower stride length and higher stride frequency could be reflected as a more stable BW walking strategy in maintaining balance(Elboim-Gabyzon \& Rotchild, 2017). The underlying mechanism of better walking stability and performance during BW-BF walking could be explained by the extra signal input from the foot sole tactile system. Hallemans et al.,(Hallemans, Ortibus, Meire, \& Aerts, 2010) also reported a shorter stride length and less trunk flexion gait pattern in subjects with visual impairment or blindfolded subjects with normal vision. The reduced visual input is suggested in a more cautious walking strategy with the foot contact the ground for haptic exploration. BW-BF walking may receive more information from the available sensory system which compensates for the decline in input from the visual system. The increased stride frequency and decreased stride length in BW-BF compared with BW-SH walking may also demonstrate an additional strategy for receiving more information from the foot sole with higher frequency to feeling the ground.

In general, the foot motions (HF/TB, FF/HF and HX/FF) observed in FW-BF and FW-SH walking was consistent with previous studies(Damavandi, Dixon, \& Pearsall, 2010)(Nicholson et al., 2018). In this study, the characteristics of $\mathrm{HF} / \mathrm{TB}, \mathrm{FF} / \mathrm{HF}$ and $\mathrm{HX} / \mathrm{FF}$ angular displacement patterns were also found similar in FW and time-reversed BW walking patterns under SH and BF conditions. While the selected crucial points of foot inter-segment angles 
during the stance phase were significantly different between FW and time-reversed BW. For the $\mathrm{HF} / \mathrm{TB}$ angles, only $\mathrm{BF} / \mathrm{SH}$ conditions effects were observed in the HF/TB maximum plantarflexion angle. Which indicates a flatter foot placement at initial contact under BF condition compared to SH(Lohman, Balan Sackiriyas, \& Swen, 2011). Footwear has been shown to hinder the kinesthesia while barefoot locomotion observed a greater awareness of foot position. Maximum HF/TB and FF/HF dorsiflexion angles were found significantly increased in BW compared to FW. Lee et al.,(Lee, Kim, Son, \& Kim, 2013) also reported an increased peak ankle dorsiflexion angle in time-reversed BW $\left(17.9^{\circ} \pm 2.0\right)$ compared with FW $\left(14.8^{\circ} \pm 2.3\right)$. For a normal barefoot walking gait, the calcaneus inverted about $2^{\circ}$ in an inverted position when the heel struck (HS) the ground, which showed slightly lateral of center(Hunt, M. Smith, Torode, \& Keenan, 2001). While at heel off (HO) in BW, the HF/TB were more everted. For the frontal plane of $\mathrm{FF} / \mathrm{HF}$ angles, BW was also found more pronated at toe contact (TC) and higher maximum pronation angles under both BF and SH conditions. An everted foot position was demonstrated from the HF/TB and FF/HF frontal plane angle patterns during BW walking. During BW, the participants' anticipation of an increased challenge to medial-lateral balance and lack of visual information may have manifested. Initial corrective backward walking $\mathrm{FF} / \mathrm{HF}$ pronated toe contact posture and $\mathrm{HF} / \mathrm{TB}$ everted heel off posture indicate a more cautious stepping pattern compared to FW(Powell, Long, Milner, \& Zhang, 2011). This inference has been verified with larger foot contact area in the medial side in BW. These differences in the FF/HF frontal plane angles correspond to conformational changes inside the foot to permit the maximum forefoot plantar surface contact with the ground during BW. Restriction in the transverse plane ROM of the HF/TB and FF/HF due to reduced foot 
flexibility, which may compensate for medial-lateral body balance and comfortable locomotion in BW. The junction of the hallux/forefoot $(\mathrm{HX} / \mathrm{FF})$ is also a major component of the multisegment foot model, which showed the kinematics of the first metatarsophalangeal (MTP) joint. The sagittal plane $\mathrm{HX} / \mathrm{FF}$ angles differed for $\mathrm{FW}$ and $\mathrm{BW}$ at $\mathrm{HC} / \mathrm{HO}$ correspond to the toe clear need for FW walking. Toe clearance was regarded as a subtle but effective behavior adaption to support foot clearance during FW walking(Mills, Barrett, \& Morrison, 2008).

Different muscle activation patterns between FW and BW may be the intrinsic factor inducing different foot motion patterns. Decreased HX/FF dorsiflexion angle was observed under SH conditions. The windlass mechanism of the foot is dependent on dorsiflexion of the MTP joint at initial contact to increase plantar aponeurosis tension and in turn inverts the hindfoot. Wolf et al.,(Wolf et al., 2008) observed significantly reduced medial longitudinal arch length in shod walking compared to barefoot walking, which suggested that the shoes inhibit the windlass mechanism. While this study failed to find any difference in foot torsion ROM between BF/SH conditions. Morio et al.,(Morio et al., 2009) suggested that more flexible shoes do not change foot motion as much as conventional shoes. In summary, by using the Oxford multi-segment foot model, small yet consistent variations in foot inter-segment angle patterns were distinguishable between FW and BW walking patterns under BF and SH conditions. Main changes in the HF/TB and FF/HF patterns were observed most conspicuous in the frontal and transverse planes, respectively. Increased pronation of $\mathrm{FF} / \mathrm{HF}$ and eversion of $\mathrm{HF} / \mathrm{TB}$ sequentially during BW walking ensure sufficient plantar/outsole to ground contact area to maintain balance without disturbing the upper body movements. Restriction in $\mathrm{HX} / \mathrm{FF}$ dorsiflexion at $\mathrm{HO}$ in $\mathrm{BW}$ walking induce less plantar aponeurosis tension, which implies 
inhibition of the windlass mechanism in BW walking. The foot torsion was not disturbed under shod conditions in this current study. Therefore, more flexible shoes or barefooted should be recommended for BW locomotion in general.

The plantar pressure distribution has been previously utilized to analyze foot function. In this study, an obvious FF/HF pronation in the first half stance and HF/TB eversion in the late stance was observed when walking backward resulting in pronated foot placement. Therefore, this increase in pronation when walking backward could be explained by increased contact area in the big toe (BT) and medial forefoot (MFF) while decreased contact area in the lateral forefoot (LFF) and midfoot (MF). The increased surface area of the foot at contact in BW reducing the risk of a slip. Walking barefoot displaying higher plantar pressure in the central forefoot (CFF), and lateral forefoot (LFF) and $\mathrm{H}$ regions in both FW and BW walking. Peak plantar pressure in habitually barefoot subjects was observed to be lower in the heel and metatarsal regions compared to shod walking. An increased peak plantar pressure were observed when walking barefoot compared with shoes under the metatarsal heads and calcaneus for habitually shod walkers(Zhang, Paquette, \& Zhang, 2013). This suggested that an acute transfer to barefoot walking for habitually shod walkers would correspond to increased plantar pressures in some plantar sub-regions especially in the forefoot and heel regions in both FW and BW walking.

Several limitations concerning this study should not be ignored. Firstly, all subjects were males, which was originally for the purpose of alleviating gender-related locomotion functional differences. Secondly, foot inter-segment kinetics were not included in this study, as the OFM foot model is a kinematic only model. Thirdly, electromyography (EMG) of the lower 
402

403

404

405

406

407

408

409

410

411

412

413

414

415

416

417

418

extremity muscles were not included in this study for BW walking analysis. Future studies should focus on foot inter-segment kinetics and EMG during BW walking with shoes and barefoot. The longitudinal training effect from backward and barefoot walking need to be considered.

\section{6}

\section{Conclusion}

In conclusion, the present study shows differences in spatiotemporal parameters, foot intersegment kinematics, plantar sub-sections peak pressures and contact areas between FW and BW under BF and SH conditions. The increased stride frequency and decreased stride length may be a strategy for BW-BF walking receiving more information from the plantar sensory system which compensates for the decline in visual cue input. The foot inter-segment motion analysis of BW has rarely been studied previously. In the current study, increased pronation of FF/HF in loading response and eversion of HF/TB sequentially in BW-BF walking combined with medially distributed plantar pressure ensure sufficient contact area between plantar and ground to maintain balance. Decreased HX/FF dorsiflexion at HO in BW induces less plantar aponeurosis tension which may inhibit the windlass mechanism compared to FW walking. Based on the findings of this study, BW rehabilitation or training under the barefoot condition is highly recommended for better proprioception with the ground.

\section{References}

Bollens, B., Crevecoeur, F., Detrembleur, C., Warlop, T., \& Lejeune, T. M. (2014). Variability of human gait: Effect of backward walking and dual-tasking on the presence 
of long-range autocorrelations. Annals of Biomedical Engineering, 42(4), 742-750. https://doi.org/10.1007/s10439-013-0961-9

426

Chard, A., Greene, A., Hunt, A., Vanwanseele, B., \& Smith, R. (2013). Effect of thong style flip-flops on children's barefoot walking and jogging kinematics. Journal of Foot and Ankle Research. https://doi.org/10.1186/1757-1146-6-8

Choi, J. T., \& Bastian, A. J. (2007). Adaptation reveals independent control networks for human walking. Nature Neuroscience. https://doi.org/10.1038/nn1930

D’Août, K., Pataky, T. C., De Clercq, D., \& Aerts, P. (2009). The effects of habitual footwear use: Foot shape and function in native barefoot walkers. Footwear Science. https://doi.org/10.1080/19424280903386411

Damavandi, M., Dixon, P. C., \& Pearsall, D. J. (2010). Kinematic adaptations of the hindfoot, forefoot, and hallux during cross-slope walking. Gait and Posture. https://doi.org/10.1016/j.gaitpost.2010.07.004

Elboim-Gabyzon, M., \& Rotchild, S. (2017). Spatial and temporal gait characteristics of elderly individuals during backward and forward walking with shoes and barefoot. Gait and Posture. https://doi.org/10.1016/j.gaitpost.2016.12.007

Fritz, N. E., Worstell, A. M., Kloos, A. D., Siles, A. B., White, S. E., \& Kegelmeyer, D. A. (2013). Backward walking measures are sensitive to age-related changes in mobility and balance. Gait and Posture, 37(4), 593-597. https://doi.org/10.1016/j.gaitpost.2012.09.022

Fu, F., Zhang, Y., Shu, Y., Ruan, G., Sun, J., Baker, J., \& Gu, Y. (2016). Lower limb mechanics during moderate high-heel jogging and running in different experienced 
wearers. Human Movement Science, 48(818), 15-27. https://doi.org/10.1016/j.humov.2016.04.002

Grasso, R., Bianchi, L., \& Lacquaniti, F. (1998). Motor patterns for human gait: backward versus forward locomotion. J Neurophysiol, 80, 1868-1885. https://doi.org/10.1007/s002210050274

Grood, E. S., \& Suntay, W. J. (1983). A Joint Coordinate System for the Clinical Description of Three-Dimensional Motions: Application to the Knee. Journal of Biomechanical Engineering. https://doi.org/10.1115/1.3138397

Hallemans, A., Ortibus, E., Meire, F., \& Aerts, P. (2010). Low vision affects dynamic stability of gait. Gait and Posture. https://doi.org/10.1016/j.gaitpost.2010.07.018

Hunt, A. E., M. Smith, R., Torode, M., \& Keenan, A. M. (2001). Inter-segment foot motion and ground reaction forces over the stance phase of walking. Clinical Biomechanics. https://doi.org/10.1016/S0268-0033(01)00040-7

Jansen, K., De Groote, F., Massaad, F., Meyns, P., Duysens, J., \& Jonkers, I. (2012). Similar muscles contribute to horizontal and vertical acceleration of center of mass in forward and backward walking: implications for neural control. Journal of Neurophysiology, 107(12), 3385-3396. https://doi.org/10.1152/jn.01156.2011

Katsavelis, D., Mukherjee, M., Decker, L., \& Stergiou, N. (2010). Variability of lower extremity joint kinematics during backward walking in a virtual environment. Nonlinear Dynamics, Psychology, and Life Sciences, 14(2), 165-178.

Kennedy, P. M., \& Inglis, J. T. (2002). Distribution and behaviour of glabrous cutaneous receptors in the human foot sole. Journal of Physiology. 
Lee, M., Kim, J., Son, J., \& Kim, Y. (2013). Kinematic and kinetic analysis during forward and backward walking. Gait and Posture, 38(4), 674-678. https://doi.org/10.1016/j.gaitpost.2013.02.014

Lohman, E. B., Balan Sackiriyas, K. S., \& Swen, R. W. (2011). A comparison of the spatiotemporal parameters, kinematics, and biomechanics between shod, unshod, and minimally supported running as compared to walking. Physical Therapy in Sport, 12(4), 151-163. https://doi.org/10.1016/j.ptsp.2011.09.004

Lythgo, N., Wilson, C., \& Galea, M. (2009). Basic gait and symmetry measures for primary school-aged children and young adults whilst walking barefoot and with shoes. Gait and Posture. https://doi.org/10.1016/j.gaitpost.2009.07.119

Mei, Q., Fernandez, J., Fu, W., Feng, N., \& Gu, Y. (2015). A comparative biomechanical analysis of habitually unshod and shod runners based on a foot morphological difference. Human Movement Science, 42, 38-53. https://doi.org/10.1016/j.humov.2015.04.007

Mills, P. M., Barrett, R. S., \& Morrison, S. (2008). Toe clearance variability during walking in young and elderly men. Gait and Posture. https://doi.org/10.1016/j.gaitpost.2007.10.006

Morio, C., Lake, M. J., Gueguen, N., Rao, G., \& Baly, L. (2009). The influence of footwear on foot motion during walking and running. Journal of Biomechanics, 42(13), 20812088. https://doi.org/10.1016/j.jbiomech.2009.06.015

Nicholson, K., Church, C., Takata, C., Niiler, T., Chen, B. P. J., Lennon, N., ... Miller, F. 
(2018). Comparison of three-dimensional multi-segmental foot models used in clinical gait laboratories. Gait and Posture. https://doi.org/10.1016/j.gaitpost.2018.05.013

Pothrat, C., Authier, G., Viehweger, E., Berton, E., \& Rao, G. (2015). One- and multisegment foot models lead to opposite results on ankle joint kinematics during gait: Implications for clinical assessment. Clinical Biomechanics. https://doi.org/10.1016/j.clinbiomech.2015.03.004

Powell, D. W., Long, B., Milner, C. E., \& Zhang, S. (2011). Frontal plane multi-segment foot kinematics in high- and low-arched females during dynamic loading tasks. Human Movement Science. https://doi.org/10.1016/j.humov.2010.08.015

Rose, D. K., Demark, L., Fox, E. J., Clark, D. J., \& Wludyka, P. (2018). A Backward Walking Training Program to Improve Balance and Mobility in Acute Stroke: A Pilot Randomized Controlled Trial. Journal of Neurologic Physical Therapy, 42(1), 12-21. https://doi.org/10.1097/NPT.0000000000000210

Sedhom, M. G. (2017). Backward Walking Training Improves Knee Proprioception in Non Athletic Males. International Journal of Physiotherapy, 4(1), 33-37. https://doi.org/10.15621/ijphy/2017/v4i1/136161

Shu, Y., Gu, Y., Mei, Q., Ren, X., Popik, S., \& Fernandez, J. (2016). Movement Analysis of Lower Limb During Backward Walking with Unstable Intervention. Journal of Medical and Biological Engineering, 36(5), 718-725. https://doi.org/10.1007/s40846-016-01664

Stebbins, J., Harrington, M., Thompson, N., Zavatsky, A., \& Theologis, T. (2006). Repeatability of a model for measuring multi-segment foot kinematics in children. Gait 
Sun, D., Mei, Q., Baker, J. S., Jia, X., \& Gu, Y. (2017). A Pilot Study of the Effect of Outsole Hardness on Lower Limb Kinematics and Kinetics during Soccer Related Movements. Journal of Human Kinetics, 57(1), 17-27. https://doi.org/10.1515/hukin-2017-0043

Tseng, I. J., Jeng, C., \& Yuan, R. Y. (2012). Comparisons of forward and backward gait between poorer and better attention capabilities in early Parkinson’s disease. Gait and Posture, 36(3), 367-371. https://doi.org/10.1016/j.gaitpost.2012.03.028

Van Deursen, R. W. M., Flynn, T. W., McCrory, J. L., \& Morag, E. (1998). Does a single control mechanism exist for both forward and backward walking? Gait and Posture, 7(3), 214-224. https://doi.org/10.1016/S0966-6362(98)00007-1

Wang, R., Thur, C. K., Gutierrez-Farewik, E. M., Wretenberg, P., \& Broström, E. (2010). One year follow-up after operative ankle fractures: A prospective gait analysis study with a multi-segment foot model. Gait and Posture. https://doi.org/10.1016/j.gaitpost.2009.10.012

Winter, D. a. (1984). Kinematic and kinetic patterns in human gait: Variability and compensating effects. Human Movement Science. https://doi.org/10.1016/01679457(84)90005-8

Winter, D. A., Pluck, N., \& Yang, J. F. (1989). Backward walking: A simple reversal of forward walking? Journal of Motor Behavior, 21(3), 291-305. https://doi.org/10.1080/00222895.1989.10735483

Wolf, S., Simon, J., Patikas, D., Schuster, W., Armbrust, P., \& Döderlein, L. (2008). Foot motion in children shoes-A comparison of barefoot walking with shod walking in 
Zhang, X., Paquette, M. R., \& Zhang, S. (2013). A comparison of gait biomechanics of flipflops, sandals, barefoot and shoes. Journal of Foot and Ankle Research, 6(1), 1-9. https://doi.org/10.1186/1757-1146-6-45

539

Figure Legends

541

542

Figure 1. Experimental set-up (not on scale)

Figure 2. Foot inter-segment kinematics during FW and time-reversed BW under barefoot and shod conditions.

Figure 3. Effect of walking patterns (FW vs. BW) and shoe conditions (BF vs. SH) on peak pressure. Notes. "P” means main effect of walking pattern; “C” means main effect of shoe condition; $\mathrm{P} \times \mathrm{C}$ means interaction. condition. 


\section{Table Legends}

560 Table 1. Means \pm SD of the Spatial-temporal parameters of FW and BW under BF and SH 561 conditions $(\mathrm{N}=16)$.

\begin{tabular}{|c|c|c|c|c|c|c|}
\hline \multirow[t]{2}{*}{ Variables } & \multirow[b]{2}{*}{ Pattern } & \multirow[b]{2}{*}{$\mathrm{BF}$} & \multirow[b]{2}{*}{ SH } & \multicolumn{3}{|c|}{ ANOVA } \\
\hline & & & & Pattern & Condition & $\begin{array}{l}\text { Pattern } \times \\
\text { Condition }\end{array}$ \\
\hline \multirow{2}{*}{ Speed (m/s) } & FW & $1.34 \pm 0.05$ & $1.37 \pm 0.06$ & $F=48.032$ & $F=2.984$ & $\mathrm{~F}=0.652$ \\
\hline & BW & $1.08 \pm 0.07$ & $1.12 \pm 0.11$ & $P<0.001$ & $\mathrm{P}=0.088$ & $\mathrm{P}=0.440$ \\
\hline \multirow{2}{*}{ SL (m) } & FW & $1.30 \pm 0.08$ & $1.33 \pm 0.05$ & $F=8.573$ & $F=26.552$ & $\mathrm{~F}=0.962$ \\
\hline & BW & $1.40 \pm 0.13$ & $1.44 \pm 0.11$ & $P=0.004$ & $\mathbf{P}<0.001$ & $\mathrm{P}=0.331$ \\
\hline \multirow{2}{*}{ SF (steps/min) } & FW & $108.9 \pm 6.6$ & $105.1 \pm 7.5$ & $F=87.181$ & $F=23.382$ & $F=2.982$ \\
\hline & BW & $96.7 \pm 8.1$ & $93.2 \pm 7.2$ & $P<0.001$ & $\mathbf{P}<0.001$ & $\mathrm{P}=0.088$ \\
\hline \multirow{2}{*}{ ST (s) } & FW & $0.69 \pm 0.02$ & $0.71 \pm 0.03$ & $F=34.042$ & $\mathrm{~F}=1.442$ & $\mathrm{~F}=0.014$ \\
\hline & BW & $0.80 \pm 0.04$ & $0.79 \pm 0.06$ & $P<0.001$ & $\mathrm{P}=0.234$ & $\mathrm{P}=0.909$ \\
\hline
\end{tabular}

562 Notes. "SL” represents stride length; "SF” represents stride frequency; "ST” represents stance 563 time. 
571 Table 2. Means \pm SD of the hindfoot relative to tibia angles $(\mathrm{HF} / \mathrm{TB})\left({ }^{\circ}\right)$ during stance phase 572 of FW and time-reversed BW under BF and SH conditions $(\mathrm{N}=16)$.

\begin{tabular}{|c|c|c|c|c|c|c|c|}
\hline Variables & & & & & & ANOVA & \\
\hline Planes & Event & Pattern & $\mathrm{BF}$ & SH & Pattern & Condition & $\begin{array}{l}\text { Pattern } \times \\
\text { Condition }\end{array}$ \\
\hline \multirow{10}{*}{ Sagittal } & \multirow[t]{2}{*}{$\mathrm{HC} / \mathrm{HO}$} & FW & $-1.2 \pm 6.0$ & $2.2 \pm 5.3$ & $F=24.651$ & $\mathrm{~F}=0.962$ & $\mathrm{~F}=0.482$ \\
\hline & & BW & $-4.8 \pm 7.4$ & $-5.6 \pm 8.8$ & $\mathbf{P}<0.001$ & $\mathrm{P}=0.331$ & $\mathrm{P}=0.489$ \\
\hline & \multirow[t]{2}{*}{ Max DF } & FW & $12.4 \pm 7.1$ & $14.9 \pm 8.9$ & $F=23.014$ & $F=17.682$ & $\mathrm{~F}=0.591$ \\
\hline & & BW & $18.6 \pm 9.8$ & $21.0 \pm 11.4$ & $\mathbf{P}<0.001$ & $\mathbf{P}<\mathbf{0 . 0 0 1}$ & $\mathrm{P}=0.462$ \\
\hline & \multirow[t]{2}{*}{ Max PF } & FW & $-9.2 \pm 6.0$ & $-6.1 \pm 5.3$ & $\mathrm{~F}=2.692$ & $F=24.832$ & $\mathrm{~F}=2.753$ \\
\hline & & BW & $-7.8 \pm 7.4$ & $-5.8 \pm 6.8$ & $\mathrm{P}=0.105$ & $\mathbf{P}<0.001$ & $\mathrm{P}=0.102$ \\
\hline & \multirow[t]{2}{*}{$\mathrm{TO} / \mathrm{TC}$} & FW & $6.2 \pm 5.2$ & $7.2 \pm 4.9$ & $\mathrm{~F}=0.841$ & $F=3.980$ & $\mathrm{~F}=1.062$ \\
\hline & & BW & $9.4 \pm 6.3$ & $8.8 \pm 5.5$ & $\mathrm{P}=0.362$ & $\mathrm{P}=0.077$ & $\mathrm{P}=0.303$ \\
\hline & \multirow[t]{2}{*}{$\mathrm{ROM}(\mathrm{DF} / \mathrm{PF})$} & FW & $21.5 \pm 7.5$ & $21.0 \pm 9.3$ & $F=18.805$ & $\mathrm{~F}=4.693$ & $\mathrm{~F}=1.073$ \\
\hline & & BW & $25.7 \pm 10.4$ & $26.8 \pm 8.7$ & $\mathbf{P}<0.001$ & $\mathrm{P}=0.058$ & $\mathrm{P}=0.305$ \\
\hline \multirow{8}{*}{ Frontal } & \multirow[t]{2}{*}{$\mathrm{HC} / \mathrm{HO}$} & FW & $3.9 \pm 5.3$ & $2.0 \pm 4.6$ & $F=26.842$ & $F=37.442$ & $F=7.593$ \\
\hline & & BW & $-1.8 \pm 4.3$ & $-3.0 \pm 5.1$ & $\mathbf{P}<0.001$ & $\mathbf{P}<0.001$ & $\mathrm{P}=0.022$ \\
\hline & \multirow[t]{2}{*}{ Max IV } & FW & $5.6 \pm 4.6$ & $4.5 \pm 5.5$ & $F=13.963$ & $\mathrm{~F}=2.982$ & $\mathrm{~F}=0.758$ \\
\hline & & BW & $8.7 \pm 4.6$ & $7.1 \pm 6.2$ & $\mathbf{P}<0.001$ & $\mathrm{P}=0.124$ & $\mathrm{P}=0.407$ \\
\hline & \multirow[t]{2}{*}{ Max EV } & FW & $-4.8 \pm 4.4$ & $-6.8 \pm 5.1$ & $F=5.645$ & $\mathrm{~F}=0.047$ & $\mathrm{~F}=0.281$ \\
\hline & & BW & $-4.3 \pm 4.9$ & $-6.0 \pm 5.5$ & $P=0.042$ & $\mathrm{P}=0.264$ & $\mathrm{P}=0.602$ \\
\hline & \multirow[t]{2}{*}{ ROM (IV/EV) } & FW & $10.4 \pm 7.7$ & $11.3 \pm 8.4$ & $\mathrm{~F}=0.813$ & $\mathrm{~F}=0.101$ & $\mathrm{~F}=3.399$ \\
\hline & & BW & $13.0 \pm 7.2$ & $13.1 \pm 6.8$ & $\mathrm{P}=0.128$ & $\mathrm{P}=0.753$ & $\mathrm{P}=0.098$ \\
\hline \multirow{8}{*}{ Transverse } & \multirow[t]{2}{*}{$\mathrm{HC} / \mathrm{HO}$} & FW & $2.5 \pm 3.6$ & $1.2 \pm 3.4$ & $F=26.093$ & $\mathrm{~F}=0.164$ & $\mathrm{~F}=0.384$ \\
\hline & & BW & $-4.6 \pm 5.1$ & $-3.1 \pm 6.7$ & $\mathbf{P}<0.001$ & $\mathrm{P}=0.697$ & $\mathrm{P}=0.539$ \\
\hline & \multirow[t]{2}{*}{ Max IR } & FW & $10.2 \pm 4.4$ & $7.9 \pm 4.8$ & $F=94.215$ & $\mathrm{~F}=1.613$ & $\mathrm{~F}=3.402$ \\
\hline & & BW & $6.8 \pm 5.1$ & $4.7 \pm 6.7$ & $\mathbf{P}<0.001$ & $\mathrm{P}=0.212$ & $\mathrm{P}=0.098$ \\
\hline & \multirow[t]{2}{*}{ Max ER } & FW & $-10.2 \pm 2.9$ & $-10.8 \pm 3.1$ & $F=35.055$ & $\mathrm{~F}=4.563$ & $\mathrm{~F}=0.212$ \\
\hline & & BW & $-5.8 \pm 4.6$ & $-6.1 \pm 4.2$ & $\mathbf{P}<\mathbf{0 . 0 0 1}$ & $\mathrm{P}=0.064$ & $\mathrm{P}=0.656$ \\
\hline & \multirow[t]{2}{*}{ ROM (IR/ER) } & FW & $20.4 \pm 9.5$ & $18.7 \pm 6.9$ & $F=38.365$ & $\mathrm{~F}=0.362$ & $\mathrm{~F}=2.414$ \\
\hline & & BW & $12.6 \pm 5.8$ & $10.8 \pm 6.3$ & $\mathbf{P}<\mathbf{0 . 0 0 1}$ & $\mathrm{P}=0.561$ & $\mathrm{P}=0.161$ \\
\hline
\end{tabular}

573 Notes. $\mathrm{HC}=\mathrm{FW}$ heel contact; $\mathrm{HO}=\mathrm{BW}$ heel-off; $\mathrm{TO}=\mathrm{FW}$ toe-off; $\mathrm{TC}=\mathrm{BW}$ toe contact;

574 DF=dorsiflexion; $\mathrm{PF}=$ plantarflexion; IV=inversion; $\mathrm{EV}=$ eversion; $\mathrm{IR}=$ internal rotation;

575 ER=external rotation; $\mathrm{SP}=$ supination; $\mathrm{PR}=$ pronation; ROM=range of motion. 
576 Table 3. Means \pm SD of the forefoot with respect to hindfoot angles (FF/HF) $\left(^{\circ}\right)$ during stance 577 phase of FW and time-reversed BW under BF and SH conditions $(\mathrm{N}=16)$.

\begin{tabular}{|c|c|c|c|c|c|c|c|}
\hline Variables & & & & & & ANOVA & \\
\hline Planes & Event & Pattern & $\mathrm{BF}$ & $\mathrm{SH}$ & Pattern & Condition & $\begin{array}{l}\text { Pattern } \times \\
\text { Condition }\end{array}$ \\
\hline \multirow{8}{*}{ Sagittal } & $\mathrm{HC} / \mathrm{HO}$ & FW & $-7.1 \pm 4.6$ & $-5.6 \pm 3.8$ & $\mathrm{~F}=0.175$ & $\mathrm{~F}=3.063$ & $\mathrm{~F}=1.226$ \\
\hline & & BW & $-6.4 \pm 4.3$ & $-4.5 \pm 3.5$ & $\mathrm{P}=0.678$ & $\mathrm{P}=0.195$ & $\mathrm{P}=0.297$ \\
\hline & Max DF & FW & $5.8 \pm 3.5$ & $7.1 \pm 4.4$ & $\mathrm{~F}=0.813$ & $\mathrm{~F}=0.644$ & $\mathrm{~F}=0.361$ \\
\hline & & BW & $7.5 \pm 4.7$ & $9.1 \pm 5.1$ & $\mathrm{P}=0.128$ & $\mathrm{P}=0.428$ & $\mathrm{P}=0.563$ \\
\hline & TO/TC & FW & $-0.7 \pm 3.5$ & $3.6 \pm 5.6$ & $F=79.806$ & $F=55.564$ & $F=9.164$ \\
\hline & & BW & $7.5 \pm 4.7$ & $9.1 \pm 5.1$ & $P<0.001$ & $\mathbf{P}<0.001$ & $P=0.014$ \\
\hline & $\mathrm{ROM}(\mathrm{DF} / \mathrm{PF})$ & FW & $12.9 \pm 4.2$ & $13.1 \pm 4.9$ & $\mathrm{~F}=1.193$ & $\mathrm{~F}=1.579$ & $\mathrm{~F}=4.024$ \\
\hline & & BW & $13.6 \pm 3.8$ & $13.5 \pm 5.5$ & $\mathrm{P}=0.305$ & $\mathrm{P}=0.244$ & $\mathrm{P}=0.076$ \\
\hline \multirow{8}{*}{ Frontal } & Max SP & FW & $6.3 \pm 3.4$ & $4.1 \pm 5.1$ & $F=21.392$ & $\mathrm{~F}=0.818$ & $\mathrm{~F}=0.194$ \\
\hline & & BW & $2.8 \pm 3.8$ & $2.7 \pm 3.7$ & $P<0.001$ & $\mathrm{P}=0.128$ & $\mathrm{P}=0.662$ \\
\hline & Max PR & FW & $-1.3 \pm 3.7$ & $-2.9 \pm 4.3$ & $F=25.813$ & $\mathrm{~F}=0.494$ & $\mathrm{~F}=0.502$ \\
\hline & & BW & $-5.8 \pm 4.8$ & $-4.1 \pm 5.2$ & $\mathbf{P}<0.001$ & $\mathrm{P}=0.482$ & $\mathrm{P}=0.484$ \\
\hline & TO/TC & FW & $0.6 \pm 2.5$ & $0.3 \pm 3.1$ & $F=18.732$ & $\mathrm{~F}=0.642$ & $\mathrm{~F}=0.844$ \\
\hline & & BW & $-5.2 \pm 3.6$ & $-3.1 \pm 5.2$ & $P<0.001$ & $\mathrm{P}=0.428$ & $\mathrm{P}=0.362$ \\
\hline & ROM (SP/PR) & FW & $7.6 \pm 4.5$ & $7.0 \pm 5.2$ & $\mathrm{~F}=2.672$ & $\mathrm{~F}=2.023$ & $\mathrm{~F}=1.043$ \\
\hline & & BW & $8.6 \pm 4.1$ & $6.8 \pm 3.7$ & $\mathrm{P}=0.105$ & $\mathrm{P}=0.191$ & $\mathrm{P}=0.345$ \\
\hline \multirow{8}{*}{ Transverse } & $\mathrm{HC} / \mathrm{HO}$ & FW & $0.6 \pm 6.9$ & $-2.1 \pm 5.3$ & $F=58.952$ & $F=33.288$ & $\mathrm{~F}=0.997$ \\
\hline & & BW & $3.2 \pm 4.9$ & $0.5 \pm 5.5$ & $P<0.001$ & $\mathbf{P}<0.001$ & $\mathrm{P}=0.344$ \\
\hline & Max ABD & FW & $-3.2 \pm 4.0$ & $-4.9 \pm 4.2$ & $\mathrm{~F}=3.626$ & $\mathrm{~F}=2.564$ & $\mathrm{~F}=1.287$ \\
\hline & & BW & $-3.9 \pm 3.8$ & $-4.8 \pm 4.6$ & $\mathrm{P}=0.089$ & $\mathrm{P}=0.143$ & $\mathrm{P}=0.286$ \\
\hline & Max ADD & FW & $6.7 \pm 6.9$ & $3.6 \pm 5.3$ & $F=73.388$ & $F=87.207$ & $F=3.688$ \\
\hline & & BW & $3.2 \pm 4.9$ & $0.5 \pm 5.5$ & $\mathbf{P}<0.001$ & $\mathbf{P}<\mathbf{0 . 0 0 1}$ & $\mathrm{P}=0.087$ \\
\hline & ROM & FW & $9.9 \pm 6.8$ & $8.5 \pm 6.2$ & $F=19.159$ & $\mathrm{~F}=0.957$ & $F=28.261$ \\
\hline & (ADD/ABD) & BW & $7.1 \pm 4.1$ & $5.3 \pm 5.8$ & $\mathbf{P}<0.001$ & $\mathrm{P}=0.353$ & $\mathbf{P}<0.001$ \\
\hline
\end{tabular}

578 Notes. HC=FW heel contact; HO=BW heel-off; $\mathrm{TO}=\mathrm{FW}$ toe-off; $\mathrm{TC}=\mathrm{BW}$ toe contact;

579 DF=dorsiflexion; $\quad \mathrm{PF}=$ plantarflexion; $\mathrm{SP}=$ supination; $\quad \mathrm{PR}=$ pronation; $\quad \mathrm{ABD}=$ abduction; $580 \mathrm{ADD}=$ adduction; ROM=range of motion. 
582 Table 4. Means \pm SD of the hallux relative to forefoot $(\mathrm{HX} / \mathrm{FF})$ angles $\left(^{\circ}\right)$ during stance phase 583 of FW and time-reversed BW under BF and SH conditions $(\mathrm{N}=16)$.

\begin{tabular}{lllllll}
\hline Variables & & & & & ANOVA & \\
\hline \multirow{2}{*}{ Events } & Pattern & BF & SH & Pattern & Condition & $\begin{array}{l}\text { Pattern } \times \\
\text { Condition }\end{array}$ \\
\hline HC/HO & FW & $22.4 \pm 11.5$ & $16.9 \pm 10.3$ & $\mathbf{F}=\mathbf{2 5 . 9 9 0}$ & $\mathbf{F}=\mathbf{2 8 . 4 8 3}$ & $\mathrm{F}=\mathbf{1 . 5 8 4}$ \\
& BW & $7.4 \pm 8.9$ & $4.7 \pm 5.6$ & $\mathbf{P}<\mathbf{0 . 0 0 1}$ & $\mathbf{P}<\mathbf{0 . 0 0 1}$ & $\mathrm{P}=0.212$ \\
Max DF & FW & $29.8 \pm 9.2$ & $23.8 \pm 10.3$ & $\mathbf{F}=\mathbf{3 9 . 9 3 8}$ & $\mathbf{F}=\mathbf{2 6 . 9 4 1}$ & $\mathrm{F}=1.262$ \\
& BW & $24.4 \pm 8.6$ & $24.8 \pm 7.9$ & $\mathbf{P}<\mathbf{0 . 0 0 1}$ & $\mathbf{P}<\mathbf{0 . 0 0 1}$ & $\mathbf{P}=0.290$ \\
Max PF & FW & $2.4 \pm 6.0$ & $2.7 \pm 5.5$ & $\mathbf{F}=\mathbf{3 3 . 9 7 3}$ & $\mathrm{F}=0.703$ & $\mathrm{~F}=1.225$ \\
& BW & $4.5 \pm 4.9$ & $1.2 \pm 5.2$ & $\mathbf{P}<\mathbf{0 . 0 0 1}$ & $\mathbf{P}=0.404$ & $\mathrm{P}=0.274$ \\
ROM (DF/PF) & FW & $27.4 \pm 8.1$ & $21.1 \pm 9.5$ & $\mathbf{F}=\mathbf{2 6 . 5 5 4}$ & $\mathbf{F}=\mathbf{7 . 1 7 7}$ & $\mathbf{F}=\mathbf{2 4 . 6 4 3}$ \\
& BW & $19.9 \pm 7.6$ & $23.6 \pm 8.4$ & $\mathbf{P}<\mathbf{0 . 0 0 1}$ & $\mathbf{P}=\mathbf{0 . 0 0 9}$ & $\mathbf{P}<\mathbf{0 . 0 0 1}$ \\
\hline
\end{tabular}

584 Notes: $\mathrm{HC}=\mathrm{FW}$ heel contact; $\mathrm{HO}=\mathrm{BW}$ heel-off; $\mathrm{TO}=\mathrm{FW}$ toe-off; $\mathrm{TC}=\mathrm{BW}$ toe contact;

585 DF=dorsiflexion; $\mathrm{PF}=$ plantarflexion; ROM=range of motion. 